\title{
EL GNÓSTICO Y LA CAPACIDAD CONFUTATORIA DE LA PALABRA COMO RECURSO DE LA LABOR MEDICINAL EN EVAGRIO PÓNTICO
}

\author{
Santiago Hernán VázQuez \\ https://orcid.org/0000-0002-2388-7172 \\ Universidad Nacional de Cuyo \\ Consejo Nacional de Investigaciones Científicas y Técnicas \\ bttp://dx.doi.org/10.15304lag.39.2.5969
}

\section{Resumen}

En el marco de los estudios contemporáneos acerca del pensamiento de Evagrio Póntico, el presente estudio procura examinar un aspecto del tópico general "Enfermedad y terapéutica del alma" en el pensador del Ponto. El aspecto que —en el marco de dicho tópico- nos interesa abordar aquí es el referente al reconocimiento evagriano de la capacidad confutatoria de la palabra como recurso terapéutico frente a la enfermedad del alma. La palabra tiene, para nuestro autor, una potencialidad terapéutica que puede ser actualizada por el llamado "gnóstico". Éste, que conoce por experiencia el desorden de los pensamientos y pasiones inherente al alma caída, puede y debe aportar una palabra que cura al desenmascarar y desarticular el núcleo pasional subyacente. El gnóstico es, además, un puente entre el alma enferma y la Palabra sagrada permitiendo que aquélla se vea en ésta configurando — bajo su influjo- su mundo cognitivo y afectivo.

Palabras clave: gnóstico, palabra, Evagrio Póntico, confutación.

\section{Abstract}

In the framework of contemporary studies on the Evagrius Ponticus' thought, the present study seeks to examine an aspect of the general topic "Sickness and therapeutics of the soul" in the Ponto's thinker. The aspect that —in the framework of this topic- I'm interested in studying here, is the one referring to the evagrian recognition of the word's confutatory

Recibido: 12/04/2019. Aceptado: 11/06/2019. 
capacity as a therapeutic resource against the disease of the soul. The word has, for our author, a therapeutic potential that can be used by the so-called "gnostic". The gnostic - who knows by experience the disorder of thoughts and passions inherent in the fallen soul- can and should provide a word that heals because it unmasks and dismantles the underlying passional core. The gnostic is, in addition, a bridge between the sick soul and the Sacred Word. In effect, the gnostic makes it possible for that soul to see itself in the Word and to configure its cognitive and affective world under its influence.

Keywords: Gnostic, word, Evagrius Ponticus, confutation.

\section{Introducción}

En el marco de los estudios contemporáneos acerca del pensamiento de Evagrio Póntico, el monje filósofo del siglo IV d.C, nos interesa, en el presente estudio, examinar un aspecto del tópico general "Enfermedad y terapéutica del alma" en el pensador del Ponto el cual ha recibido, con distintas modulaciones, la atención de los especialistas ${ }^{1}$. El aspecto que, en el marco

${ }^{1}$ Aunque dicha denominación sea de nuestra factura, la misma designa un conjunto de temas característicos de la obra evagriana que han sido objeto de investigación durante las últimas décadas. En efecto, nos encontramos con abundantes y valiosas contribuciones en torno, por ejemplo, a dos temas que se vinculan al tópico de la enfermedad del alma en tanto resultan manifestaciones de la misma. Nos referimos a los tópicos de la acedia y de los logismoi. En el caso de la primera podemos mencionar los siguientes estudios: Bunge, 1991; Forthomme, 2000; 2003, pp. 21-26; 2005, pp. 15-35; Luciani-Zidane, 2009; Peretó Rivas, 2018; 2012, pp. 23-35; 2015, pp. 581-593; Despland, 2013, pp. 71-80. En el caso de los logismoi, mencionemos solo algunos: Corrigan, 2016, pp. 49-72; Gibbons, 2015, pp. 297-330; Horyacha, 2013, pp. 113-147; Tsakiridis, 2010; Pesthy, 2003, pp. 1017-1022. Una mención especial merecen trabajos como los de Inbar Graiver (2016; 2018), Rubén Peretó Rivas (2017a) y Smaranda Buju (2019) entre otros, los cuales se ocupan de visualizar las confluencias y articulaciones conceptuales que se pueden establecer entre los desarrollos evagrianos y algunos enfoques de la psicología contemporánea como el de la ACT (Acceptance and Commitment Therapy), el del Mindfulness o de la Terapia Cognitivo-Conductual.

En lo que se refiere al aspecto terapéutico, además de algunos de los aquí citados que también tratan el tema, consignaremos en el cuerpo del artículo algunos que constituyen antecedentes directos de nuestro estudio.

Por otro lado no podemos olvidarnos de las referencias realizadas por Michel Foucault a nuestro autor, inscriptas en la línea de su proyecto genealógico, abocado en el caso de Evagrio al tema de los logismoi y su sujeto. Remitimos en esta caso a nuestro trabajo recientemente publicado en Revista de Historia de la Psicología (Vazquez, 2019) en el que nos detenemos un momento en las menciones que realiza el pensador francés acerca del monje del Ponto. Allí señalamos entre otras cosas lo siguiente: "Es en este último tomo de su 'Historia de la sexualidad' ['Les aveux de la chair'] donde Foucault —habiéndose ocupado ya, en su indagación genealógica, del pensamiento griego clásico (filosófico y médico) y de los textos helénicos y latinos de los primeros siglos de nuestra era- se detiene en los primeros siglos del cristianismo y del rol que, a su entender, juegan, en la experiencia que el 
de dicho tópico, nos interesa abordar aquí es el referente al reconocimiento evagriano de la capacidad confutatoria de la palabra como recurso terapéutico frente a la enfermedad del alma.

Estudiosos del pensamiento del pensador del Ponto, como Augustine Casiday (2013, pp. 120-121, 126-128, 131-132), Carol Harrison (2011, p. 211), George Tsakiridis (2010, pp. 38, 79), Julia Konstantinovsky (2009, p. 57) Antoine Guillaumont (1996; 2009, pp. 191-192, 244-259) Luke Dysinger (2005), Bernard Forthomme (2000, pp. 123, 350-351, 498, 543, 571), Gabriel Bunge (1997, pp. 77-105), David Brakke (2009, pp. 1-40) y Michael O'Laughlin (1992, pp. 201-215), entre otros, se han ocupado del tópico de la acción curativa que Evagrio asigna a la palabra de los salmos en particular y de la Sagrada Escritura en general. En efecto, apropiándose originalmente de una tradición clásica y cristiana ${ }^{2}$, el monje del Ponto reconoce que la palabra posee una virtualidad curativa que puede ser actualizada de distintos modos. La Sagrada Escritura y los salmos en particular, ofrecen una palabra que puede ser terapéutica en la medida que puede modificar efectivamente las pasiones y los pensamientos. El método Antirrhético creado originalmente por Evagrio, constituye el ejemplo más patente de cómo la palabra de la Sagrada Escritura puede servir para combatir pensamientos perturbadores. Pues bien, en otros lugares hemos demostrado que se puede identificar en la obra evagriana otro camino posible de actualización de la potencia terapéutica de la palabra. Un camino que, de acuerdo a nuestra hipótesis, procura de modo más directo la cura de la enfermedad propia

cristianismo tiene de la carne, 'la hermenéutica y el desciframiento purificador del deseo'. Como hemos señalado, las referencias que, en este contexto, se hacen de Evagrio son breves. La primera vincula el concepto de cogitationes de Casiano, con el de logismoi de Evagrio (Foucault, 2018, p. 135) [...] Cuando más adelante Foucault se detenga brevemente en este concepto evagriano (p. 226) será para subrayar la connotación demonológica que el término tiene en el Póntico, la cual ciertamente existe pero no agota toda la extensión del concepto.” (Vazquez, 2019, p. 46).

${ }^{2}$ En el cierre de la obra que el médico español Laín Entralgo consagra al asunto de la curación por la palabra en la Antigüedad Clásica, se lee lo siguiente: "Con la muerte de Aristóteles se acaba en Grecia la especulación original acerca de la acción psicológica de la palabra humana, y por tanto del poder curativo de ésta [...] Solo con el cristianismo — dentro del cual será llamada Logos, «Verbo», la persona divina que «se hizo carne»—comenzará una nueva posibilidad para la psicoterapia verbal; pero esta posibilidad, no más que incipiente en Gregorio de Nisa, Basilio de Capadocia y Clemente de Alejandría, tardará siglos en fructificar” $(2005$, p. 223). Cabe destacar que los tres autores cristianos mencionados por Laín son de primaria importancia en el pensamiento de Evagrio. Gregorio y Basilio son, en efecto, maestros directos del Póntico, y Clemente, una de sus principales referencias doctrinales. Respecto del tópico en este último pueden consultarse los trabajos de Druille (2009) y de Alby (2011, pp. 169-188). 
del alma ${ }^{3}$. Nos referimos a la palabra de quien en el pensamiento evagriano es llamado "gnóstico" . Éste puede realizar la labor medicinal que Evagrio le asigna en su sistema, a partir del uso terapéutico de aquella capacidad confutatoria de la palabra.

El Póntico reconoce en la palabra una serie de potencialidades terapéuticas, que solo el gnóstico, en virtud de la ciencia y la experiencia que ha alcanzado $^{5}$ al cabo de su progreso espiritual, puede actualizar.

El gnóstico puede desnudar los pensamientos malvados o logismo $i^{6}$, objetivar su engaño, descifrar la presencia de la pasión por el cuerpo o filautía ${ }^{7}$ en sus más sofisticadas elaboraciones, proponer consecuentemente una palabra refutadora, dar "una palabra de sal al impuro" (Evagrio Póntico, 2008a, p. 90), "reducir la escisión entre la palabra sagrada y la vida" (Forthomme, 2000, p. 498) poniendo aquella como la que replica y reproduce el propio drama vital.

Pueden ser identificados dos grandes caminos por los cuales el gnóstico puede contribuir a la cura de la ignorancia mediante la palabra y en los cuales se ve en acción todo aquello. El primero tiene que ver con el despliegue de la virtud confutatoria de la palabra en el marco de la lucha contra los

3 "La enfermedad propia del alma para Evagrio Póntico es la ignorancia de sí. El nous caído (tal cosa es el hombre para nuestro autor) ignora, a consecuencia de haberse desprendido de la unidad con Dios, quién es, ignora su condición espiritual y su vocación de unicidad con el Creador. Tal ignorancia engendra un amor de sí parà phýsin -llamado por Evagrio filautía $(\phi \iota \lambda \alpha v \tau \iota \alpha)$ - que posee como objeto el propio cuerpo. Dicho amor genera, a su vez, una actividad de la parte pasional del alma, también parà phýsin, que posee un correlato cognitivo rayano en lo patológico y que Evagrio denomina logismoi. Este es, en apretada síntesis, lo que podría llamarse el cuadro etiológico completo de la concepción evagriana de enfermedad del alma.” (Vazquez, 2019, p. 47).

4 "Una figura característica y distintiva del monacato cristiano primitivo es la del Abba o anciano. Éste es, en sentido lato, un monje experimentado que puede, en virtud de su progreso espiritual, ejercer un auténtico 'ministerio de la palabra'. Por este ministerio el Abba realiza una tarea de auxilio a los hombres hostigados por sus pensamientos y pasiones, y por tentaciones demoníacas. En el pensamiento de Evagrio Póntico, monje y filósofo, el $A b b a$ o anciano recibe la significativa denominación de 'Gnóstico' pues se trata del monje que ha alcanzado un cierto grado de ciencia espiritual — natural primero, sobrenatural después-al cabo de haberse ejercitado sostenidamente en el ejercicio de las virtudes (Practiké)." (Vazquez, 2017, p. 251).

${ }^{5}$ Cfr. Vazquez, 2017, p. 256 ss.

6 "Éstos [los logismoi] son, en la elaborada psicología evagriana, la actividad cognitiva característica del alma enferma o apasionada, o, como indica Forthomme, estructura lógica de las pasiones (Forthomme, 2000, p. 500). Es por esto que no es conveniente traducir el término logismoi. Este vocablo tiene siempre en Evagrio un sentido peyorativo que no sería bien expresado en la traducción correspondiente de pensamientos." (Vazquez, 2018, pp. 337-338). 
pensamientos (logismoi). El segundo, con la contribución fundamental que puede realizar su palabra para mezclar el alma con las virtudes mediante el despliegue de su virtud especular. Esto último apunta directamente a la cura de las pasiones, siempre mediante la devolución de una nueva imagen de sí. Habiéndonos ocupado ya del segundo de estos caminos (Vazquez, 2019), nos interesa abordar aquí el primero.

\section{El gnóstico y la virtud confutatoria de la palabra: la desarticulación de los razonamientos falsos}

Si hay algo que caracteriza la practiké, es decir, la primera etapa del itinerario con el que Evagrio entiende el Cristianismo, es la lucha contra los logismoi. Éstos son, como citamos recién, la actividad cognitiva característica del alma enferma en su estado postlapsario ${ }^{8}$. Pues bien, es en el marco de esta lucha - fundamental en el itinerario de curación propuesto por nuestro autor- que la contribución que realiza el gnóstico es decisiva. Esta contribución se funda en un singular reconocimiento de la virtud confutatoria-terapéutica de la palabra.

En el capítulo 43 de la obra evagriana Tratado Práctico se halla como cifrado el fundamento de este reconocimiento de la palabra en tanto reveladora y confutatoria, de la cual el gnóstico hace un uso terapéutico. Observamos en aquel capítulo que la palabra que el gnóstico debe buscar para oponer al pensamiento perturbador y para liberar al alma de él, es la que lo desenmascara, la que lo nombra y lo identifica. El gnóstico o abba, indica Evagrio en una de sus cartas a Eulogio, "debe buscar qué pensamiento se opone a tal esfuerzo" (Evagrio Póntico, 2006a, p. 75), es decir, debe afinar el arte de discernir los pensamientos para poder desnudarlos y refutarlos adecuadamente reconduciendo a su raíz pasional el razonamiento que proponen cuando sugieren postergar un esfuerzo hacia la virtud.

El logismos puede ser una construcción lógico-verbal procedente directamente de las pasiones (en rigor, como señala Forthomme, los logismoi pueden ser entendidos como la estructura lógica de las pasiones) o de una sugestión lógico-verbal demoníaca ${ }^{9}$. En cualquier caso es la palabra, en

7 Ver nota 3 .

${ }^{8}$ Ver nota 6 y cfr. Vazquez, 2018.

${ }^{9}$ El término logismoi en Evagrio designa tanto la actividad lógica que busca asegurar la satisfacción de las pasiones enfermas, cuanto las sugestiones cognitivas procedentes directamente del demonio. 
virtud de un poder develante que Evagrio tematiza en el citado capítulo 43 del Tratado Práctico, la que puede desarticular la arquitectura lógica pasional que busca profundizar la ignorancia. Para hacerlo debe, señala nuestro autor, reconocer e identificar, nombrándolos, todos los elementos que están sosteniendo dicha arquitectura: los objetos, las imágenes, las palabras, los recuerdos, las aspiraciones. La palabra comienza a desenmascarar así el logismos, el cual, a su vez, actúa, perturbando, por debajo de la conciencia. Para indicar la acción de la palabra contra el logismos, Evagrio utiliza, en el mismo capítulo, el verbo $\sigma \eta\rceil \mu \alpha i ́ \nu \omega:$ "Esto [los componentes del pensamiento], es necesario conocerlos, para que, al momento en que los logismoi comienzan a poner en marcha su materia y antes de que nosotros seamos empujados demasiado lejos del estado en que estamos, pronunciemos algunas palabras dirigidas a ellos, y denunciemos $(\sigma \eta \mu \alpha i ́ v \omega \mu \varepsilon \nu)$ al que está allí” (Evagrio Póntico, 1971, p. 600).

$\Sigma \eta \eta \alpha$ í $\nu \omega$ resulta un verbo complejo que, en efecto, ha recibido en las modernas traducciones de la obra evagriana, diversas interpretaciones. La edición francesa del Tratado Práctico ha escogido el verbo dénoncer (denunciar). Otras traducciones han utilizado, por ejemplo, los verbos señalar (Evagrio Póntico, 2008b, p. 167), reconocer (Evagrio Póntico, 1998b, p. 86) y desvelar (Evagrio Póntico, 1995b, p. 153). Todas estas traducciones contribuyen a captar el sentido en que el verbo es utilizado por Evagrio: la palabra apropiada que libera del pensamiento perturbador es la que denuncia, señala, reconoce, desvela la gramática demoníaca que se esconde en esa constelación psíquica desestabilizante. Por lo demás, resulta significativo que el verbo admita también, como indica el diccionario de Liddel y Scott, ser traducido como interpretar y explicar. Esto puede sugerir que Evagrio está indicando que esta palabra que libera es la que desarticula la lógica perversa del tentador, descomponiendo sus elementos e identificando las circunstancias en que actúa e identificando así su falsa premisa original.

Evagrio subraya más de una vez aquello de descomponer los elementos e identificar todas las circunstancias en las que actúan los pensamientos

"Al principio [los logismoi] abordan el alma con dulzura y una gran fuerza persuasiva, como si ellos tuvieran piedad del cuerpo y le prometieran alguna comodidad, pero al fin, ellos se lanzan sobre ella descaradamente, entonces ella no puede deshacerse de ellos, porque ella ha acogido las pasiones fundamentales capaces de engendrarlos" (Evagrio Póntico, 2007, p. 159).

Respecto a la condición demoníaca de algunos logismoi Evagrio señala que los demonios “como resultado del estudio, han aprendido el lenguaje de los hombres" (1985, p. 151) y es en el lenguaje interior del hombre donde concretan su ataque. Ellos soplan, dicen, sugieren palabras al oído, indica nuestro autor (2005, pp. 51-52, 54, 67-68, 86, 90, 119, 138). 
demoníacos. Esta es una labor previa a la propuesta de una palabra curativa. Por ello el gnóstico es quien puede actualizar esta potencia confutatoria o des-articulante de la palabra, pues él, como hemos señalado, ha alcanzado una amplia experiencia en el combate y la identificación de los pensamientos y puede así realizar un "diagnóstico" pertinente que lo habilita a ofrecer una palabra con efectos terapéuticos.

Evagrio insiste en que sólo la ciencia que se obtiene al cabo de dicha experiencia, habilita a ejercer la tarea de dirigir, enseñar y curar a los demás dándoles la palabra apropiada. Quien no la posee y, sin embargo, desempeña dicha labor es, dirá en el opúsculo Sobre Maestros y Discípulos, como una calle que conduce a las profundidades del infierno, o como un pastor que disloca los tobillos de sus ovejas, o como un timonero que conduce al naufragio. El adjetivo que utiliza Evagrio para referirse a este pseudognóstico es, significativamente, a) $\nu \varepsilon \pi \imath \sigma \tau \eta \mu \omega \nu$ : ignorante, sin conocimiento. Es esta ignorancia la que le impide el ejercicio de la $\delta \imath \alpha ́ \gamma \nu \omega \sigma \iota \varsigma$ de las ovejas en la niebla, dice profundizando la alegoría pastoril. Es decir, porque aún no ha alcanzado la ciencia natural y permanece ignorante, es incapaz de ver, de conocer, de distinguir, de discernir el lógos del alma de los demás. Por tanto, dice a continuación, no puede decir nada apropiado al tiempo de la tentación (Evagrio Póntico, 1997, p. 102). Situada en este contexto la metáfora de la niebla podría estar designando la atmósfera psicológica propia de la tentación y la confusión que generan las pasiones impidiendo —a sí mismo y a los demás- contemplar claramente el lógos del alma. Quien lo contempla puede, por el contrario, dar la palabra apropiada al tiempo de la tentación.

En esta labor el gnóstico puede ayudarse de los sueños del alma enferma en tanto éstos "suministran un buen diagnóstico sobre el estado de salud del ama" (Guillaumont, 2009, p. 274). Refoulé afirma, en este sentido, que "los sueños deben ser puestos al servicio de la dirección espiritual" (1961, p. 512) en la medida en que "el director espiritual es médico del alma" y, por otro lado, que los sueños "de manera privilegiada develan las pasiones" (1961, p. 496 $)^{10}$.

En cualquier caso, para realizar esa $\delta \imath \alpha ́ \gamma \nu \omega \sigma \imath \varsigma$, el gnóstico debe tener la experiencia del combate contra los pensamientos y la ciencia que se le otorga al cabo de sostener largamente dicho combate.

${ }^{10}$ Evagrio dedica una sección del Tratado Práctico (1971, pp. 624-632) a tratar acerca de lo que acontece en los sueños como indicio de la pasión dominante y del estado del alma. También en otras como el tratado Sobre los Pensamientos, se extiende en este tópico (1998a, pp. 248-256). Un artículo reciente acerca del tema es el siguiente: Peretó Rivas, 2017b. 
Por ello, si alguien quiere llegar a ser gnóstico, "que observe los pensamientos, que remarque sus tensiones, sus relajamientos, sus entrelazamientos, sus momentos, cuáles demonios hacen esto o aquello, qué demonio sigue a continuación de tal otro y cuál no le sigue; y que inquiera al lado de Cristo las razones de las cosas" (Evagrio Póntico, 1971, p. 614).

De este modo puede hacer que el enemigo de vuelta contra sí mismo su propia espada, la de su palabra tentadora. Pero para ello debe, como decimos, conocer los detalles de las maquinaciones diabólicas y pasionales: "Cuando uno de los enemigos te visita para herirte y tu quieres, como está escrito, 'dar vuelta contra su corazón su propia espada' (Sal. 36, 15), actúa como sigue. Divide en ti el pensamiento que él te ha enviado: ¿qué es pues? ¿De cuántos elementos se compone y cuál es el que entre ellos más atormenta al intelecto?” (Evagrio Póntico, 1998a, pp. 216-218).

Es precisamente en esta última obra citada, el tratado Sobre los pensamientos, que Evagrio retoma la temática de la virtud confutatoria de la palabra que el gnóstico debe actualizar para realizar una contribución terapéutica en la lucha contra los pensamientos. En el capítulo nueve, en el marco de la descripción del demonio vagabundo, el Póntico se detiene en el tópico. La palabra que aleja el logismos malvado — indica allí — no debe ser pronunciada prematuramente pues su efecto puede ser contraproducente. El gnóstico debe observar cómo actúa dicho logismos, donde empieza, donde cursa y donde termina. La palabra a pronunciar contra él debe desnudarlo y desenmascararlo completamente: si ella se propone prematuramente el pensamiento puede esconderse y su objetivo puede no ser descubierto. En otro lugar Evagrio indica que el gnóstico debe "distribuir las razones a cada uno según su rango" (2008a, p. 174), es decir, la palabra que él ofrece debe adaptarse a la condición de quien la recibe. De allí la necesidad de que quien acude al gnóstico "ponga todo ante él” (Evagrio Póntico, 2006b, p. 179).

Puede existir, como señala Bamberger, un orgullo defensivo en el monje que lleva a a una falta de confidencia con el guía espiritual (el gnóstico) y aún a una reacción negativa frente a su intervención. Se trata de un orgullo que conspira contra aquella necesidad de poner todo ante el gnóstico, como subrayara el Póntico en Extractos, y contra el precepto de valorar sus palabras, de acuerdo a la carta A Eulogio (2006a, p. 74). En el fondo de este orgullo defensivo hay, expresa Bamberger, una "autoimagen negativa" por un "débil desarrollo del yo", que puede conducir a rechazar con indignación la palabra que propone el gnóstico (Bamberger, 1992, p. 194). Por ello éste debe conocer adecuadamente todos los detalles del pensamiento que se 
propone desbaratar y su lugar dentro del completo dinamismo psíquico de quien recibe su palabra. Y todo ello a fin de no pronunciar prematuramente su palabra. Debe tener claro qué concepción tiene de sí el receptor de su palabra pues se trata en última instancia de modificar esa concepción. Es por esto que Evagrio insiste en que el gnóstico debe adecuar al rango, a la dignidad $(\alpha \xi i \alpha)$ de cada uno las palabras que ofrecerá. Es decir, supone que, para ofrecer una palabra, el gnóstico debe conocer adecuadamente a aquel que la va a recibir, su dignidad en relación al conocimiento (si se ha hecho o no digno de recibirlo y en qué medida ${ }^{11}$ ), su nivel de ignorancia. En otras palabras, el grado de su enfermedad.

El gnóstico podrá realizar así un "diagnóstico" adecuado y, a partir de este diagnóstico, ofrecer la palabra que desarticule los pensamientos dominantes que pueden estar hostigando al alma:

Déjale [al pensamiento demoníaco], un día, o aún otro, llevar al término su juego, para que, después de haber aprendido a conocer en detalle sus maquinaciones, lo pongamos en huida, desenmascarándolo con una palabra [...] Observa estos detalles y entrégalos a tu memoria, a fin de poder desenmascararlo cuando se aproxime; revélale el lugar que él guarda secreto, y también que tú no le seguirás allí en lo sucesivo [...] Desenmascáralo desde que se presenta y, de una palabra, le descubrirás el primer lugar donde entró, y el segundo, y el tercero [...] Que la huida del pensamiento lejos de ti te aporte la prueba que tú le has dirigido la palabra que convenía, porque es imposible que se mantenga cuando ha sido abiertamente desenmascarado (Evagrio Póntico, 1998a, pp. 182-184).

Resulta necesario entonces, antes de iniciar cualquier intervención, conocer todos los detalles de la acción del logismos dejándole actuar un día o dos, observando de donde parte y adonde termina, contemplando su largo circuito, conociendo en detalle sus maquinaciones. De este modo se podrá escoger la palabra apropiada ante la cual el pensamiento demoníaco "huirá lejos". Evagrio utiliza esta vez, y de modo reiterado, el verbo $\dot{\varepsilon} \lambda \dot{\varepsilon} \gamma \chi \omega$ para referirse a la acción liberadora que ejerce la palabra. En este capítulo dicho término - caro, por cierto, a la tradición platónica- es utilizado cuatro veces. Nos hallamos nuevamente frente a un término complejo. Como con $\sigma \eta ̣ \mu \alpha i ́ \nu \omega$, Evagrio se esfuerza en precisar aquí en qué consiste el quehacer liberador de la palabra. Y escoge para ello un término que exprese la complejidad del mismo y las múltiples acciones o actos que lo componen. En un esfuerzo por asir el sentido en que el verbo es usado por Evagrio,

${ }^{11}$ Recordemos aquí la nocion evagriana de gnosis. Ella es un conocimiento o ciencia espiritual que se ofrece como don divino a quien ha recorrido el camino de la practiké y ha alcanzado la apátheia. A propósito puede consultarse el ya clásico "manual” sobre Evagrio de Antoine Guillaumont (2009). 
Guillaumont y Géhin proponen, en su traducción, el término desenmascarar (démasquer), como el equivalente de $\dot{\varepsilon} \lambda \dot{\varepsilon} \gamma \chi \omega$. Su propuesta, acaso de traducción no literal, contribuye, no obstante, a captar toda la implicancia semántica que Evagrio quiere dar, en el contexto de este capítulo, al verbo $\dot{\varepsilon} \lambda \dot{\varepsilon} \gamma \chi \omega$. El término desenmascarar permite designar la acción de la palabra que desnuda, descubre y refuta. Este último verbo es, en efecto, el que más inmediatamente se asocia a nuestro término y el que es usado en otras traducciones del tratado Sobre los Pensamientos ${ }^{12}$. La palabra que libera del pensamiento perturbador es la que nombrándolo, lo desenmascara, dejando al descubierto su engaño y falsedad. En efecto, un sentido que el verbo admite, de acuerdo al diccionario Liddell Scott, es el de la acción de delatar una debilidad. Y aquí también se verifica el acierto de la traducción francesa pues, en tanto la palabra pronunciada contra el logismos delata - luego de observarlo en detalle y conocer sus artimañas - sus argumentos falaces y — de nuevo- su insidioso punto de partida, desenmascara al demonio, y es ese desenmascaramiento su refutación definitiva. Más arriba indicábamos que el gnóstico puede descifrar y descubrir la presencia de la pasión por el cuerpo o filautía en sus más sofisticadas elaboraciones. La palabra desenmascarante puede, por ejemplo, estar develando dicha presencia.

La refutación es posible $-\mathrm{y}$ con ella la remediación- porque, como señala Forthomme, la seducción diabólica y las mismas pasiones tienen un elemento lógico. Por ello son en Evagrio logismoi, y por ello "son susceptibles de ser reencontrados por el impacto de una palabra" (Forthomme, 2003, p. 73).

Lo que ha de hacer el gnóstico entonces es, después de realizar un diagnóstico apropiado, destruir con una palabra apropiada los sofismas, los razonamientos falsos que buscan profundizar la ignorancia de un alma en camino hacia el conocimiento. Haciéndose eco de un texto paulino, Evagrio lo afirma expresamente: "La sabiduría es la fortaleza donde habitan los sabios, 'destruyendo los razonamientos y toda potencia orgullosa que se alza contra la ciencia de Dios' (2Cor. 10, 4)" (Evagrio Póntico, 1995c. Escolio al versículo 14 del salmo 91).

El término griego del texto bíblico usado aquí por Evagrio traducido como "razonamiento", es $\lambda \circ \gamma \_\sigma \mu o v ́ s$. Paul Géhin prefiere traducirlo como "pensamientos malvados" aun cuando el sentido del texto bíblico sea el de razonamiento. Incluso la edición española de la Biblia de Jerusalen prefiere 86-89.

12 Por ejemplo en la traducción de Francesca Moscatelli: Evagrio Póntico, 2010, pp. 
traducirlo como "sofismas". Ciertamente Géhin realiza una, por así decir, "apropiación evagriana" del término bíblico. Una apropiación que resulta legítima desde el momento en que la significación evagriana de logismoi remite, entre otras cosas, a un razonamiento falso o sofisma. Nosotros preferimos mantener el equivalente "razonamiento" para reforzar la idea que venimos desarrollando. El gnóstico, en efecto, destruye los razonamientos falsos o sofismas en que puede consistir un logismos. Con su palabra desnuda, desenmascara, descubre, señala, desvela, reconoce, desarticula y refuta las premisas falsas del argumento que da al logismos, fuerza persuasiva dentro del alma y por el cual se busca que ésta, dando curso a un movimiento parà phýsin de la parte pasional, se hunda más en la ignorancia.

\section{La confutación y la Sagrada Escritura}

Un elemento más que no se puede soslayar en el contexto de esta labor desbaratadora de los logismoi que el gnóstico lleva adelante con su palabra, es el rol que posee la Sagrada Escritura ${ }^{13}$. La Escritura, en efecto, está presente, como señala D'Ayala Valva, en todos los lugares o momentos que componen la vida monástica del desierto egipcio de los primeros siglos cristianos en los que se inscribe la labor evagriana. Y está presente de modo eminente en "la entrevista con los ancianos espirituales" (D'Ayala Valva, 2011, p. 231), "en el contexto de conversaciones entre maestro y discípulo" (Burton-Christie, 2007, p. 75).

Luke Dysinger ha demostrado que el exégeta bíblico y el guía espiritual están, en el pensamiento evagriano, profundamente interconectados. El

${ }^{13}$ Acerca de la presencia ubicua de la Sagrada Escritura en el mundo monástico en el que se inserta Evagrio (Stewart habla, en el artículo que ahora referenciaremos, de "ubicuidad de la Escritura"), existen muchas obras que se extienden ampliamente sobre el tema. Remitimos a algunas de las más importantes: Burton-Christie, 2007; D’Ayala Valva, 2011; Stewart, 2011.

Dice, por ejemplo, Burton-Christie en la citada obra: “[Existió] una poderosa influencia bíblica en el nacimiento y desarrollo del monaquismo egipcio" (p. 45). Y más adelante: "La orientación práctica de los padres del desierto implica que la interpretación de la Escritura que se refleja en los Dichos no se produce nunca porque sí, sino que está arraigada en la vida y las preocupaciones del desierto [...] Vemos la Escritura en los labios del monjes durante la oración en la soledad del desierto, en el contexto de conversaciones entre maestro y discípulo, durante combates con los demonios y en encuentros con prostitutas, sacerdotes paganos y aldeanos locales. Su uso es casi siempre práctico, espontáneo, informal y lleno de vitalidad [...] [Se trata] de una forma de vida centrada en la apropiación profunda de la Escritura" (p. 75). 
gnóstico, en efecto, debe ser guía espiritual a la luz de las Sagradas Escrituras, de las que él es el exégeta autorizado. En la Sagrada Escritura descubre en muchas ocasiones la palabra que ilumina a las almas que a él acuden. En efecto, "el principal libro de texto del gnóstico es la Biblia" (Dysinger, 2013 , p. 38). A ella y a su adecuado uso por parte del gnóstico en la labor de auxilio a otras almas, dedica Evagrio una sección de su obra El gnóstico (2008a, pp. 117-123). Indica allí el Póntico que el guía espiritual debe buscar en la Sagrada Escritura "respecto de los pasajes alegóricos o de los literales, si ellos corresponden a la practiké, a la physiké o a la theologiké" (2008a, p. 117) y así proyectarlos a la vida de las almas, como de hecho hace nuestro autor en todas sus obras exegéticas en las cuales, mediante el género de los escolios, comenta pasajes seleccionados de los textos bíblicos de Proverbios, Eclesiastés, Salmos, Evangelio de San Lucas, Job; sacando de allí enseñanzas para el camino espiritual y reflejos de las peripecias del itinerario que recorren las almas que buscan la salud. También le indica que "es bueno conocer los usos de la divina Escritura y establecerlos" (Evagrio Póntico, 2008a, p. 119).

En la Biblia, el gnóstico debe buscar los secretos del itinerario místico de las almas y, ayudado por los ángeles, descubrir lo que dicen acerca del viaje de ésta:

Como un exégeta bíblico el gnóstico de Evagrio descubre en las escrituras símbolos y alegorías del gran drama cósmico de la caída, encarnación y reunión escatológica de todos los seres racionales con Dios. Como guía espiritual el gnóstico alza la vista, por así decir, desde la Biblia, para percibir los movimientos y experiencias de cada alma como parte del 'Libro de Dios', una iteración en miniatura y reflexión del viaje cósmico universal hacia la reunión. Así el drama de cada lucha interna del alma es iluminado por los dramáticos movimientos de la historia bíblica de salvación (Dysinger, 2013, p. 49).

En las Escrituras puede, asimismo, encontrar una palabra que desenmascare los logismoi o sosiegue el movimiento pasional, y proponerla al que busca su palabra, como es el caso del método Antirrhético ${ }^{14}$. En este sentido el rol del gnóstico también puede ser definido como mediador entre la palabra sagrada y el alma enferma de ignorancia y hostigada por pensamientos y pasiones parà phýsin.

${ }^{14}$ No podemos ocuparnos aquí de todo lo que implica este método aunque necesariamente nuestro tema tenga una relación natural con el mismo pues dicho método se funda en la virtud confutatoria de la palabra. En nuestro caso nos limitamos a estudiar cómo es que el gnóstico puede actualizar la virtud confutatoria de la palabra en el marco de la labor medicinal que Evagrio le asigna. 
Dysinger lo expresa con meridiana claridad y hacemos nuestros sus asertos: "El gnóstico de Evagrio es tanto un maestro como un médico espiritual. Sus remedios curativos están sacados principalmente de las Escrituras: él es un exégeta bíblico que busca en las Escrituras una visión que lo beneficie a él mismo y a otros" (2004, p. 100).

Como la Sagrada Escritura constituye, en el mundo monástico, la instancia suprema de referencia y el fundamento mismo de la vocación escogida, su mensaje posee una fuerza y una repercusión afectivas capaces de rechazar un pensamiento obsesivo o socavar una creencia irracional. Por lo demás, en este recurso a las Escrituras por el que Evagrio funda el método para combatir los pensamientos malvados —el llamado método Antirrhético- se ve el arte de nuestro autor para desbrozar el mundo de los pensamientos, identificar clara y concisamente aquellos que pueden perturbar al monje y oponerle una palabra precisa en la cual el monje contemple, a la vez, el carácter ficticio del pensamiento perturbador y la posibilidad de apropiarse de otro modo de significar y pensar las situaciones de su vida.

En el opúsculo Proverbios y Comentarios refiriéndose precisamente a las palabras bellas y buenas del hombre justo (gnóstico) que son aquellos panales de miel que curan (1952, p. 166-167) ${ }^{15}$, Evagrio señala que los monjes comprenderán las palabras de Dios y descubrirán así las artimañas del demonio (1952, p. 167). Esas palabras son las que le da el gnóstico o de las que el gnóstico es mediador. Comprendiéndolas por intermedio de éste, el monje puede avanzar en el descubrimiento y la batalla contra aquellos pensamientos que lo hostigan con artimañas, engaños y sofismas.

Evagrio mismo, en carácter de maestro de su discípulo Anatolio, prescribe a éste el uso de la Sagrada Escritura para combatir los pensamientos.

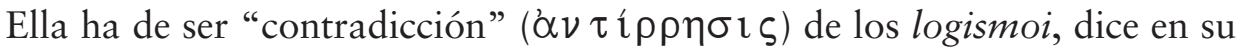
carta al discípulo (Evagrio Póntico, 1995a. Carta 25, punto 2), remitiendo sin duda a la obra entera que él ha dedicado a esta práctica. En dicha obra,

${ }^{15}$ Respecto a la imagen de la miel como símbolo de la palabra que cura encontramos también en el corpus evagriano el siguiente texto:

"Por 'la hormiga', Salomón nos describe probablemente la vida práctica, mientras que por la 'abeja' designa la contemplación de las creaturas y del Creador mismo, que puros e impuros, sabios e insensatos 'llevan a su boca para la salud' de su alma. Considero también que la cera corresponde a las realidades mismas, mientras que la miel que ellas contienen es el símbolo de su contemplación. Y la cera pasará, porque es dicho: 'El cielo y la tierra

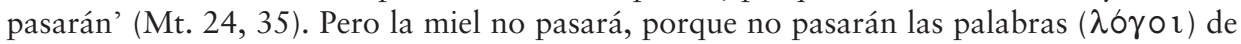
Cristo nuestro Salvador, de quien Salomón habla en estos términos: 'Las buenas palabras

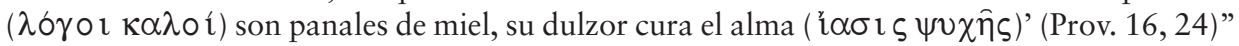
(Evagrio Póntico, 1987, pp. 168-170). 
en efecto, Evagrio se encarga de seleccionar diversos textos de la Sagrada Escritura que sirven de confutación directa a las sugestiones concretas y variopintas de los ocho logismoi. Y fundamenta en todo lo que hemos venido diciendo la propuesta de este método.

Dado que en la hora de la lucha no hallamos rápidamente en la Escritura las palabras idóneas para confutar a nuestros enemigos, los pérfidos demonios, pues éstas se encuentran desperdigadas y es difícil localizarlas, hemos compilado diligentemente las palabras de las Santas Escrituras para que nos armemos de ellas y procedamos con valor contra los 'filisteos' (Ex. 13,17), de pie en la batalla como valientes y vigorosos soldados de Jesucristo, nuestro victorioso rey (Evagrio Póntico, 2005, p. 48).

La Escritura es así una de los principales recursos con que cuenta el gnóstico para llevar adelante su labor terapéutica. En gran parte dicha labor consiste en ser un puente entre la Sagrada Escritura y el alma enferma, ayudando a ésta a descubrir en el libro sagrado tanto la palabra que apacigua sus pasiones y desarticula los razonamientos de éstas, cuanto la propia aventura espiritual y el propio rostro del alma. Por ello D'Ayala Valva llega a afirmar que

El contacto y la familiaridad con tales personas [los ancianos o abbas] son considerados como decisivos en el camino de asimilación de la Palabra [...] porque ésta consiste en una palabra viviente, que sigue encarnándose [...] [La palabra del abba] actualiza, vivifica y permite redescubrir de manera siempre nueva la Palabra de Dios contenida en las Escrituras (2011, pp. 243-244).

Un ejemplo en la obra evagriana de cómo el gnóstico es quien enseña el modo de asimilar la palabra es, precisamente, el dicho de un gnóstico (un apotegma) que nuestro autor trae hacia el final del Tratado Práctico: "Un hermano poseía solamente un evangelio; habiéndolo vendido, dio el precio para alimentar a los hambrientos, profiriendo esta palabra memorable: Yo he vendido, dijo, el libro mismo que me decía: 'Vende lo que posees y dalo en precio a los pobres"” (1971, p. 704).

La Escritura debe hacerse vida. Las pasiones, los pensamientos y las conductas deben ser moldeados de acuerdo a la Sagrada Escritura. Esto era lo que enseñaba el gnóstico, transformándose en un puente entre el libro sagrado y el alma enferma.

\section{Conclusiones}

Como lo hemos señalado reiteradamente Evagrio, reconoce en la palabra - a la zaga de una tradición clásica y cristiana bien identificada- una serie de potencialidades terapéuticas, que solo el gnóstico, en virtud de la 
ciencia y la experiencia que ha alcanzado al cabo de su progreso espiritual, puede actualizar. El gnóstico puede desnudar los pensamientos malvados o logismoi, objetivar su engaño, descifrar la presencia de la pasión por el cuerpo o filautía en sus más sofisticadas elaboraciones y proponer así, consecuentemente, una palabra refutadora que nacida de su conocimiento profundo del alma enferma, puede tener efectos terapeúticos. En efecto, hemos visto que lo que hace dicha palabra es descomponer los elementos del pensamiento perturbador, desarticulando su lógica pasional, identificado la raíz pasional de la premisa de la que dicha actividad cognitiva parte. El conocimiento profundo del alma enferma que acude al gnóstico es requisito de su intervención verbal: el "diagnóstico" pertinente lo habilita a ofrecer una palabra con efectos terapéuticos y ese diagnóstico es posible por ser el gnóstico quien es y por conocer a la "oveja" que a él acude. Lo que ha de hacer el gnóstico entonces es, después de realizar un diagnóstico apropiado, destruir con una palabra apropiada los sofismas, los razonamientos falsos que buscan profundizar la ignorancia de un alma en camino hacia el conocimiento.

Asimismo el gnóstico tiene como principal fuente de su labor terapéutica la Sagrada Escritura de tal manera que él se constituye en una especie de puente entre el alma enferma y la palabra sagrada. En las Escrituras el gnóstico busca los secretos del itinerario místico de las almas y puede encontrar una palabra que desenmascare los logismo $i$ o sosiegue el movimiento pasional, y proponerla al que busca su palabra, como es el caso del así llamado Método Antirrhético, fundado en el reconocimiento de todo aquel dinamismo de la palabra confutatoria y en el lugar que ocupa la Sagrada Escritura en la vida cristiana.

\section{Bibliografía}

Alby, J. C. (2015). La medicina filosófica del Cristianismo antiguo. Santa Fe: Universidad Católica de Santa Fe.

Bamberger, J. E. (1992). Desert Calm Evagrius Ponticus: the Theologian as Spiritual Guide. Cistercian Studies Quaterly 27 (3), 185-198.

Brakke, D. (2009). Introduction. En Evagrius Ponticus, Talking Back: A Monastic Handbook for Combating Demons (1-40). Minnesota: Liturgical Press. 
Buju, S. (2019). Clinical Approach of Spiritual Illnesses: Eastern Christian Spirituality and Cognitive Behavioral Therapy. Pastoral Psychology (Springer). https://doi.org/10.1007/s11089-019-00874-5

Bunge, G. (1991). Akèdia: La doctrine spirituelle d'Évagre le Pontique sur l'Acédie. Spiritualité orientale 52. Bégrolles en Mauges, Maine-et-Loire: Abbaye de Bellefontaine.

Bunge, G. (1997). Commentary on the Prologue of the Antirrhetikos by Evagrius of Pontus. Studia Monastica 39/1, 77-105.

Burton-Christie, D. (2007). La palabra en el desierto. La Escritura y la búsqueda de la santidad en el antiguo monaquismo cristiano. Madrid: Siruela.

Casiday, A. (2013). Reconstructing the theology of Evagrius Ponticus: Beyond heresy. Cambridge: Cambridge University Press. https://doi.org/10.1017/CBO9781139051347

Corrigan, K. (2016). Thoughts that Cut; Cutting, Imprinting, and Lingering in Evagrius of Ponticus, en J. Kalvesmaki and R. D. Young (eds.), Evagrius and His Legacy. South Bend, University of Notre Dame Press: 49-72. https://doi.org/10.2307/j.ctvpj7dsk.7

D’Ayala Valva, L. (2011). 'Dans le miroir des Écritures': la Bible dans l'expérience spirituelle des Pères du desert. Proche-Orient Chrétien 61 (3-4), 229-257.

Despland, J.-N. (2013). La tristesse en présence de Dieu: de l'acédie à la mélancolie, Psychothérapies, 33, 71-80. https://doi.org/10.3917/ psys.132.0071

Druille, P. (2009). El poder sanador de la palabra en Clemente de Alejandría. Circe 13, 123-137.

Dysinger, L. (2004). Healing Judgment: 'Medical Hermeneutics' in the Writing of Evagrius Ponticus. En M. Bielawski y D. Hombergen (eds.), Il monachesimo tra eredità e aperture: atti del simposio "Testi e temi nella tradizione del monachesimo cristiano". Roma: Pontificio ateneo S. Anselmo.

Dysinger, L. (2005). Psalmody and Prayer in the Writings of Evagrius Ponticus. New York: Oxford University Press. https://doi. org/10.1093/0199273200.001.0001

Dysinger, L. (2013). An Exegetical Way of Seeing: Contemplation and Spiritual Guidance in Evagrius Ponticus. Studia Patristica 57, 31-50.

Evagrio Póntico (1952). Proverbes et Commentaires. En J. Muyldermans (ed.) Evagrius Ponticus. Evagriana syriaca: Textes inedits du British Museum et de la Vaticane [Unpublished texts of the British Museum and the Vatican]. Bibliothèque du Muséon 31. Louvain: Publications universitaires. 
Evagrio Póntico (1971). Traité pratique ou le moine. Tomo II. Edición, traducción y comentarios de A. Guillaumont y C. Guillaumont. Sources Chrétiennes 171. Paris: Cerf.

Evagrio Póntico (1985). Les six centuries des 'Kephalaia gnostica' d'Évagre le Pontique. Traducción de Antoine Guillaumont, Patrologia Orientalis T. XXVIII, fascicule 1. Paris: Brepols.

Evagrio Póntico (1987). Scholies aux Proverbes [Scholia to Proverbs]. Introducción, traducción y notas de Paul Géhin, Sources Chrétiennes 340. Paris: Cerf.

Evagrio Póntico (1995a). Letters. Texto parcial del original griego y traducción al ingles en: L. Dysinger, "St. Evagrius Ponticus (345-399). Selected Letters", Monastic Spirituality Self-Study (Website): http://www.ldysinger.com/Evagrius/11 Letters/00a start.htm.

Evagrio Póntico (1995b). Obras espirituales. Introducción, traducción y notas de José I. González Villanueva y Juan Pablo Rubio Sadia. Madrid: Ciudad Nueva.

Evagrio Póntico (1995c). Scholia on Psalms. Texto parcial del original griego y traducción al ingles en: L. Dysinger, "St. Evagrius Ponticus (345-399). Selected Scholia on Psalms", Monastic Spirituality Self-Study (Website): http://www.ldysinger.com/Evagrius/08 Psalms/00a start.htm.

Evagrio Póntico (1996). Gli otto spiriti della malvagità. Sui diversi pensieri della malvagità. Introducción, traducción y notas de Francesca Moscatelli. Milano: San Paolo.

Evagrio Póntico (1997). On Teachers and Disciples. En G. Gould, An Ancient Monastic Writing Giving Advice to Spiritual Directors (Evagrius of Pontus, On Teachers and Disciples). Hallel 22, 100-103. Textos griegos sobre los que se basa la traducción de Gould: Van den Veld (1908). Un opuscule inédit attribué à S. Nil. En Mèlanges Godefroid Kurth (73-81), Liège, Bibliothèque de la Faculté de Philosophie et lettres de l'Université de Liège. Correcciones al texto texto griego: Muyldermans, J. (1942). Le De Magistris et Discipulis de S. Nil, Quelques Corrections Textuelles. Le Musèon 55.

Evagrio Póntico (1998a). Sur les pensées. Introducción, traducción y notas de Paul Géhin, Claire Guillaumont y Antoine Guillaumont, Sources Chrétiennes 438. Paris: Cerf.

Evagrio Póntico (1998b). Trattato Pratico sulla vita monástica. Introducción de traducción de Lorenzo Dattrino. Roma: Città Nuova.

Evagrio Póntico (2005). Contro i pensieri malvagi. Antirrhetikos. Introducción de Gabriel Bunge, traducción y notas de Valerio Lazzeri. Magnano: Qiqajon. 
Evagrio Póntico (2006a). A Eulogio. Sulla confessione dei pensieri e consigli di vita. Introducción, traducción y notas de Lucio Coco. Milano: San Paolo.

Evagrio Póntico (2006b). Excerpts. En A. Casiday (Trad.), Evagrius Ponticus (172-180) London and New York: Routledge.

Evagrio Póntico (2007). Chapitres des disciples d’Évagre. Edición, traducción y comentarios de Paul Géhin, SC 514. Paris: Cerf.

Evagrio Póntico (2008a). Le gnostique ou a calui qui est devenu digne de la science. Introducción, traducción y notas de Antoine Guillaumont y Claire Guillaumont, Sources Chrétiennes 356. Paris: Cerf.

Evagrio Póntico (2008b). Trattato Pratico. Introducción y traducción de Gabriel Bunge. Magnano: Qiqajon.

Evagrio Póntico (2010). Gli otto spiriti della malvagità. Sui diversi pensieri della malvagità. Introducción y traducción de Francesca Moscatelli. Milano: San Paolo.

Forthomme, B. (2000). De l'acédie monastique à l'anxio-dépression: histoire philosophique de la transformation d'un vice en pathologie. Paris: Synthélabo.

Forthomme, B. (2003). L'expérience de la guérison. Paris: Les Empêcheurs de penser en rond.

Forthomme, B. (2005). Émergence et résurgence de l'acédie. In N. Nabert (ed.), Tristesse, acédie et médecine des âmes dans la tradition monastique et cartusienne: anthologie de textes rares et inédits, XIIIe-XXe siècle (15-35). Paris: Beauchesnes.

Foucault, M. (2018). Les aveux de la chair. París: Gallimard.

Gibbons, K. (2015). Passions, Pleasures, and Perceptions: Rethinking Evagrius Ponticus on Mental Representation. Journal of Ancient Christianity, 19 (2), 297-330. https://doi.org/10.1515/zac-2015-0019

Graiver, I. (2016). The Paradoxical Effects of Attentiveness. The Journal of Early Christian Studies 24 (2), 199-227. https://doi.org/10.1353/ earl.2016.0017

Graiver, I. (2018). Possible Selves in Late Antiquity: Ideal Selfhood and Embodied Selves in Evagrian Anthropology. The Journal of Religion 98 (1), 59-89. https://doi.org/10.1086/694589

Guillaumont, A. (1996). Études Sur La Spiritualité De L'orient Chrétien. Bégrolles-en-Mauges: Abbaye de Bellefontaine.

Guillaumont, A. (2009). Un philosophe au désert. Évagre le Pontique. Paris: Vrin. 
Harrison, C. (2011). Enchanting the soul: the music of the psalms. En A. Andreopoulos, A. Casiday y C. Harrison (eds.), Meditations of the Heart: The Psalms in Early Christian Thought and Practice (205-224). Turnhout: Brepols. https://doi.org/10.1484/M.STT-EB.4.7011

Horyacha, M. (2013). Monastic Thought on the Passions: Pseudo-Macarius versus Evagrius Ponticus. Byzantion 83, 113-147

Konstantinovsky, J. (2009). Evagrius Ponticus. The Making of a Gnostic. Farnham: Ashgate.

Laín Entralgo, P. (2005). La curación por la palabra en la Antigüedad Clásica. Barcelona: Anthropos.

Luciani-Zidane, L. (2009). L'acédie. Le vice de forme du christianisme. De saint Paul à Lacan. Paris: Cerf.

O'Laughlin, M. W. (1992). The Bible, Demons and the Desert: Evaluating the Antirrheticus of Evagrius Ponticus. Studia Monastica 34 (2), 201-215.

Peretó Rivas, R. (2012). Evagrio Póntico y la exclaustración de la acedia. Carthaginensia: Revista de estudios e investigación, 28 (53), 23-35.

Peretó Rivas, R. (2015). La acedia como causa de la caída del nous en Orígenes y Evagrio Póntico. Teología y vida, 55, 581-593. https://doi.org/10.4067/S0049-34492014000400001

Peretó Rivas, R. (2017a). ACT (Acceptance and Commitment Therapy) y Evagrio Póntico. Algunas correspondencias teóricas. Cauriensia 12, 579-598.

Peretó Rivas, R. (2017b). Dreams in Evagrius Ponticus' Life and teaching. Vox Patrum, 37, 523-542. https://doi.org/10.31743/vp.3413

Peretó Rivas, R. (2018). Evagrio Póntico y la acedia. Berna: Peter Lang. https://doi.org/10.3726/b10851

Pesthy, M. (2003). Logismoi Origéniens - Logismoi Évagriens. En L. Perrone, P. Bernardino y D. Marchini (eds.), Origeniana Octava (1017-1022). Leuven: Leuven University Press/Peeters.

Refoulé, F. (1961). Rêves et vie spirituelle d'après Évagre le Pontique. Supplément de la Vie Spirituelle, 59, 470-516.

Stewart, C. (2011). The use of biblical texts in prayer and the formation of monastic culture. American Benedictine Review 62 (2), 188-201.

Tsakiridis, G. (2010). Evagrius Ponticus and Cognitive Science: A Look at Moral Evil and the Thoughts. Oregon: Pickwick Publications. 
Vazquez, S. H. (2017). El abba como Gnóstico en Evagrio Póntico: el rol pedagógico-medicinal de su palabra y sus fuentes. Studia Monastica 59 (2), 251-268.

Vazquez, S. H. (2018). La enfermedad del alma en el filósofo tardoantiguo Evagrio Póntico: entre ignorancia y filautía. Anales del Seminario de Historia de la Filosofía 35 (2), 323-343. https://doi.org/10.5209/ ASHF.59657

Vazquez, S. H. (2019). Aportes para una historia de la metáfora del espejo. el horizonte logo-terapéutico de su tematización en Evagrio Póntico y otros autores tardoantiguos. Revista de Historia de la Psicología, 40(1), 45-54. https://doi.org/10.5093/rhp2019a4 